\title{
Endothelium-dependent vasodilation effects of Panax notoginseng and its main components are mediated by nitric oxide and cyclooxygenase pathways
}

\author{
YANYAN WANG ${ }^{1,2}$, YU REN ${ }^{1,2}$, LEILEI XING ${ }^{1,2}$, XIANGDONG DAI ${ }^{1,2}$, SHENG LIU $^{3}$, BIN YU $^{1,2}$ and YI WANG ${ }^{1,2}$ \\ ${ }^{1}$ Institute of Traditional Chinese Medicine Research, Tianjin University of Traditional Chinese Medicine, Tianjin 300193; \\ ${ }^{2}$ Tianjin State Key Laboratory of Modern Chinese Medicine; ${ }^{3}$ Department of Physiology and Pathophysiology, \\ Tianjin Medical University, Tianjin 300070, P.R. China
}

Received October 26, 2015; Accepted October 21, 2016

DOI: $10.3892 /$ etm.2016.3890

\begin{abstract}
Panax notoginseng, a traditional Chinese herbal medicine, has been used for the treatment of cardiovascular diseases. The main bioactive components of this species are Panax notoginseng saponins (PNS). The present study aimed to investigate the effects of PNS and five of its main components (ginsenosides Rg1, Re, Rb1 and Rd, and notoginsenoside R1) on rat aorta rings pre-contracted with norepinephrine (NE) and to determine the underlying mechanism of action. Isolated aorta rings (with or without intact endothelium) from adult male Wistar rats were stimulated with $\mathrm{NE}$ to induce vasoconstriction, and subsequently treated with different concentrations of PNS and its five main components ( $\mathrm{Rg} 1, \mathrm{Re}$, $\mathrm{Rb} 1, \mathrm{R} 1$ and $\mathrm{Rd}$ ) separately. This procedure was repeated after pre-incubation with the nitric oxide (NO) synthase inhibitor $\mathrm{N}^{\mathrm{G}}$-nitro-L-arginine methyl ester (L-NAME), the guanylate cyclase inhibitor $1 \mathrm{H}-[1,2,4]$ oxadiazolo[4,3-a]quinoxalin-1-one (ODQ) and the cyclooxygenase (COX) inhibitor indomethacin (INDO), in order to elucidate the mechanism of action of PNS and its components. The results demonstrated that PNS and the components $\mathrm{Rg} 1, \mathrm{Re}, \mathrm{Rb} 1$ and $\mathrm{R} 1$, but not Rd, induced vessel relaxation in a concentration-dependent manner when the endothelium lining was intact. NO synthase inhibitor L-NAME and guanylate cyclase inhibitor ODQ attenuated the diastolic effects of PNS, Rg1, Re, Rb1 and R1 in aortic rings with intact endothelium. By contrast, INDO, a known COX inhibitor weakened the vasodilation effects of PNS, Re and $\mathrm{Rb} 1$ but demonstrated no effect on $\mathrm{Rg} 1$ and $\mathrm{R} 1$. In conclusion,
\end{abstract}

Correspondence to: Professor Yi Wang, Institute of Traditional Chinese Medicine Research, Tianjin University of Traditional Chinese Medicine, 88 Yuquan Road, Tianjin 300193, P.R. China E-mail: vip_wangyi@126.com

Key words: Panax notoginseng saponins, ginsenoside Rg1, ginsenoside Rb1, ginsenoside Re, ginsenoside Rd, notoginsenoside R1, aortic ring, nitric oxide, cyclooxygenase
PNS and two of its main components (Re and Rb1) exert vasodilating effects through the NO and COX pathways.

\section{Introduction}

Hypertension is one of the major risk factors for cardiovascular accidents (1). Its main complications include stroke, myocardial infarction, heart failure and chronic kidney disease (2-4). Hypertension is a serious threat to human health, and is one of the most actively researched areas in the biomedical field. Blood pressure is maintained by the regulation of vascular tone, which can be affected by many factors. For example, nitric oxide (NO) has been shown to be an effective vasodilator (5). Furthermore, the $\mathrm{NO}$ synthase inhibitor $\mathrm{N}^{\mathrm{G}}$-nitro-L-arginine methyl ester (L-NAME) is known to induce sustained blood pressure elevation and left ventricular hypertrophy (6). Soluble guanylyl cyclase (sGC) is an important effector of NO (7). It acts by increasing intracellular cyclic GMP (cGMP) levels to mediate numerous biological functions (8). The compound 1H-[1,2,4] oxadiazolo[4,3,-a]quinoxalin-1-one (ODQ) has been identified as a selective inhibitor of this enzyme; ODQ treatment is able to increase contractile tone and inhibit relaxation in response to authentic NO (8). Indomethacin (INDO), a known cyclooxygenase (COX) inhibitor has been reported to significantly increase mean arterial pressure without altering other hemodynamic parameters through the inhibition of vasodilation (9).

Antihypertensive drugs exert their actions through a variety of pathways that regulate blood pressure. The major effects of these drugs include: Modulation of the sympathetic branch of the peripheral nervous system and of the renin-angiotensin system (RAS); blockade of calcium channels; improvement of endothelial function; regulation of cardiac blood flow; and inhibition of vascular remodeling and increased urination (10). Antihypertensive drugs include: Diuretics, calcium channel blockers (CCBs), angiotensin-converting enzyme inhibitors (ACEIs), angiotensin II (ATII) receptor antagonists (ARBs), $\alpha 1$ receptor blockers, $\beta$-blockers, renin inhibitors, central hypotensive agents, ganglion blockers and vasodilators (11). Despite their important therapeutic effects, these drugs all have potential side effects. For example, the use of diuretic 
antihypertensive drugs can lead to hypokalemia, hyperglycemia, hypercholesterolemia, hypertriglyceridemia, and accumulation of uric acid in the blood; $\beta$-blockers can cause bronchospasm, peripheral circulation disorders, and insulin insensitivity; and ACEIs can give rise to a dry persistent cough, for example (12).

Panax notoginseng is a species of the genus Panax which is a traditional Chinese herbal medicine (13). The main bioactive ingredient of this species is Panax notoginseng saponins (PNS), which is a phytoestrogenic composition (14). It is known that PNS exerts extensive effects on the cardiovascular system, including inhibition of platelet aggregation, augmentation of the coronary blood flow, improvement of left ventricular diastolic function in hypertensive patients, and myocardial ischemia remodeling protection (15-18). PNS also reduces myocardial oxygen consumption and is endowed with antiarrhythmic effects (19-23).

PNS is a chemical mixture containing $>50$ different saponins, and the five major components of PNS are ginsenosides Rg1, Rb1, Re and Rd, and notoginsenoside R1 (24-29). PNS saponins are classified into two main groups: Namely the 20(S)-protopanaxatriol saponins (PTS) such as ginsenoside Rg1 and ginsenoside Rd; and the 20(S)-protopanaxadiol saponins (PDS) such as ginsenoside Rb1 and Re, and notoginsenoside R1 (30,31).

In the present study, the aim was to assess the role of PNS and its main components in vascular tone, and thereby explain the mechanism by which they benefit cardiovascular function. The study was conducted using in vitro aortic vascular rings. The endothelium-derived relaxing factors and pathways were examined to elucidate the vasodilation effects of PNS and its major components. This should provide an experimental basis for and improve the clinical application of PNS and its major components.

\section{Materials and methods}

Drugs and reagents. PNS, ginsenoside Rg1, ginsenoside Rb1, notoginsenoside R1, ginsenoside Re and ginsenoside Rd were provided by Zhongxin Pharmaceutical Group Corporation, Ltd. (Tianjin, China). Norepinephrine (NE), acetylcholine chloride (ACh), dimethyl sulfoxide (DMSO), L-NAME, INDO, sodium chloride $(\mathrm{NaCl}), \mathrm{ODQ}$, potassium chloride $(\mathrm{KCl})$, potassium dihydrogen phosphate $\left(\mathrm{KH}_{2} \mathrm{PO}_{4}\right)$, magnesium sulfate heptahydrate $\left(\mathrm{MgSO}_{4} \cdot 7 \mathrm{H}_{2} \mathrm{O}\right)$, sodium bicarbonate $\left(\mathrm{NaHCO}_{3}\right)$, glucose and calcium chloride $\left(\mathrm{CaCl}_{2}\right)$ were purchased from Sigma-Aldrich (Merck Millipore, Darmstadt, Germany).

Animals. Adult male Wistar rats (weight, 250-300 g), were purchased from the Experimental Animal Center, Institute of Radiation Medicine, Chinese Academy of Medical Sciences, Tianjin, China [permit: SCXK200F (JING) 0004]. Rats (8-10 weeks) were housed at $22 \pm 2{ }^{\circ} \mathrm{C}$ and a relative humidity of $40 \pm 10 \%$ under a 12-h light/dark cycle and given standard laboratory diet and water. Rats were fasted for $12 \mathrm{~h}$ before experiments but allowed to access water freely. All experimental procedures that involved animals were submitted to and approved by the Animal Ethics Committee of Tianjin University of Traditional Chinese Medicine Medical Center (permit: LAEC2013005).
Preparation of aortic rings. Male Wistar rats were sacrificed by cervical dislocation and their thoracic aortas were carefully dissected and removed. Fat and other non-vascular tissues were dissected, and the thoracic aortas were sliced into 3-4-mm ring segments after placing in Krebs-Henseleit (K-H) solution at $4^{\circ} \mathrm{C}$ (in $\mathrm{mM}$ : $\mathrm{NaCl}, 118 ; \mathrm{KCl}, 4.7 ; \mathrm{NaHCO}_{3}, 25 ; \mathrm{KH}_{2} \mathrm{PO}_{4}, 1.2$; $\mathrm{MgSO}_{4}, 1.2 ; \mathrm{CaCl}_{2}, 1.3$; glucose, 10) (32). The vessels were not stretched and the endothelium was protected during handling. For some of the rings, the endothelium was removed gently by rubbing the ring with a glass rod.

The aorta rings were mounted onto two stainless-steel stirrups immersed in a 10-ml organ chamber, containing $\mathrm{K}-\mathrm{H}$ buffer that was continuously bubbled with $95 \% \mathrm{O}_{2}$ and $5 \% \mathrm{CO}_{2}$, and maintained at $37^{\circ} \mathrm{C}$. Isometric tension change was measured with the force-displacement transducer and recorded using a PowerLab 8/30 bio-signal recording system (AD Instruments Pty Ltd., Bella Vista, Australia). The aorta rings were stretched progressively to a basal tension of $2.0 \mathrm{~g}$ and equilibrated for $90 \mathrm{~min}$; during this period the bath solution was replaced with K-H buffer every 15 min. After stabilization the rings were repeatedly contracted with $\mathrm{KCl}$ (60 mmol/l) three times until the muscle tension returned to the basal level.

The aortic rings were pre-treated with $\mathrm{NE}\left(1 \times 10^{-6} \mathrm{~mol} / \mathrm{l}\right)$ to achieve the plateau phase, and $\mathrm{ACh}\left(1 \times 10^{-5} \mathrm{~mol} / \mathrm{l}\right)$ was then added to induce vasodilation. Compared with the maximum contraction extent induced by $\mathrm{NE}$, if the relaxation extent achieved was $>60 \%$, the endothelium was regarded as intact and functional, while if it was $<10 \%$, the aorta rings would be regarded as completely denuded endothelium.

Measurement of vascular relaxation. Once a sustained contraction plateau in response to $\mathrm{NE}\left(1 \times 10^{-6} \mathrm{~mol} / \mathrm{l}\right)$ was achieved, $10 \mu \mathrm{l} \mathrm{H}_{2} \mathrm{O}$ or DMSO; PNS $(0.2,0.4,0.6$ or $0.8 \mathrm{mg} / \mathrm{ml})$; or $\mathrm{Rg} 1$, $\mathrm{Rb} 1, \mathrm{Re}, \mathrm{R} 1$ and $\mathrm{Rd}\left(1 \times 10^{-8}, 1 \times 10^{-7}, 1 \times 10^{-6}\right.$ or $\left.1 \times 10^{-5} \mathrm{~mol} / \mathrm{l}\right)$ was cumulatively added with an interval of $8 \mathrm{~min}$ to the organ bath containing the aortic rings with or without endothelium. $\mathrm{H}_{2} \mathrm{O}$ was used for PNS. DMSO was used for Rg1, Rb1, R1, Re and Rd.

In order to investigate the involvement of the endothelial NO pathway and cyclooxygenase (COX) pathway in vasorelaxation to PNS and its main five components (ginsenoside $\mathrm{Rg} 1$, Re, Rb1 and Rd, and notoginsenoside R1), the rings were exposed to $0.1 \mathrm{mmol} / 1 \mathrm{~L}-\mathrm{NAME}, 0.01 \mathrm{mmol} / 1 \mathrm{ODQ}$ and $0.01 \mathrm{mmol} / 1 \mathrm{INDO}$ for $20 \mathrm{~min}$ prior to application of NE to blunt the endothelial function by inhibiting NO and COX synthesis following repeated washout and subsequent equilibration for $45 \mathrm{~min}$.

Statistical analysis. Results are shown as mean \pm standard deviation values. Statistical comparisons were carried out by analysis of variance followed by a Dunnett's multiple comparison test. $\mathrm{P}<0.05$ was considered to indicate a statistically significant difference. Each data point represents the mean of a minimum of 10 aortic rings from different animals unless otherwise noted.

\section{Results}

Effects of solvents $\left(\mathrm{H}_{2} \mathrm{O}\right.$ and DMSO) on aortic rings. It was first verified that the solvents $\mathrm{H}_{2} \mathrm{O}$ and DMSO each had no 
A

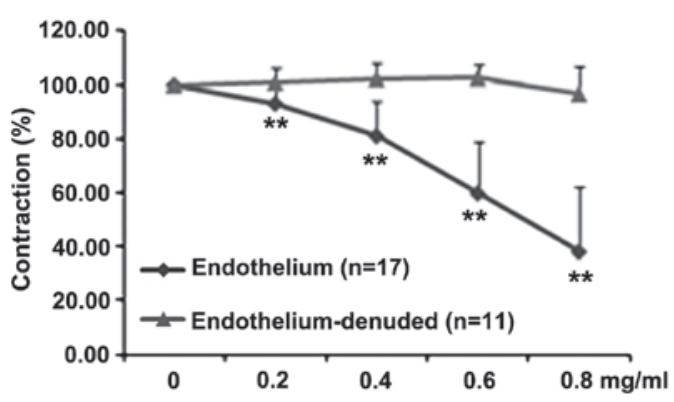

C

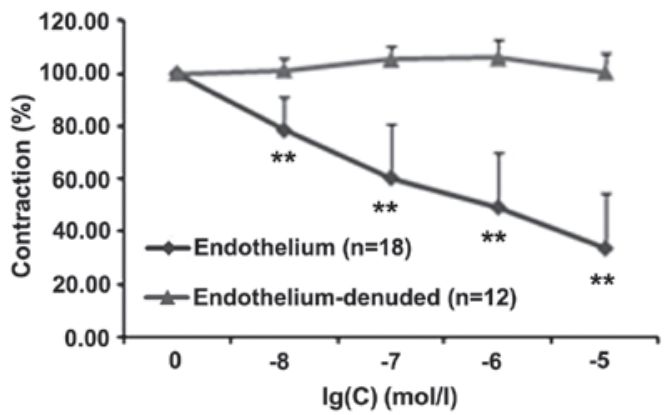

$\mathbf{E}$

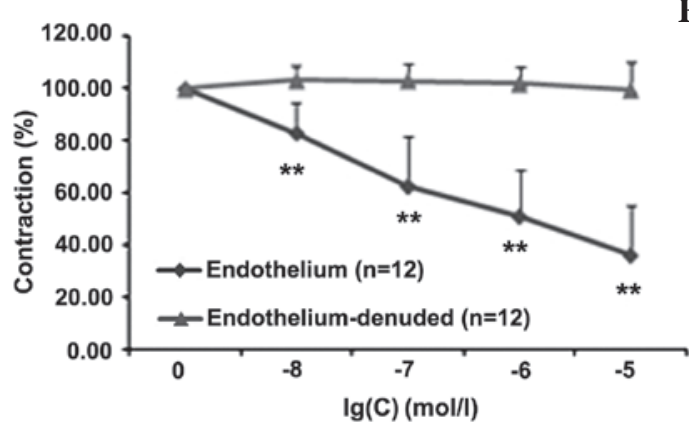

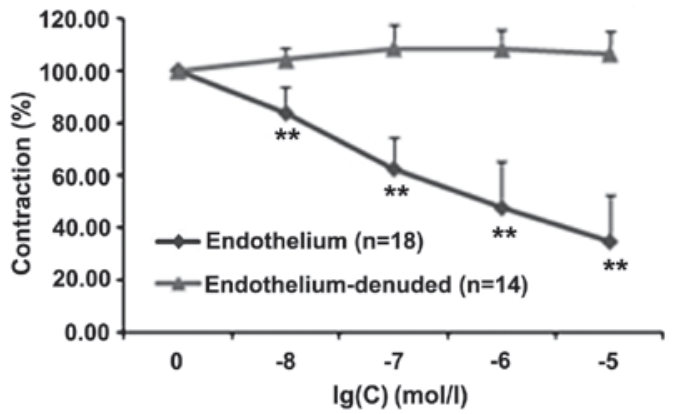

D

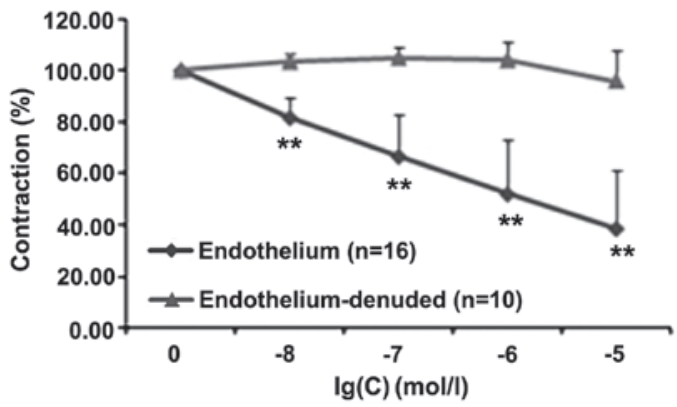

$\mathbf{F}$

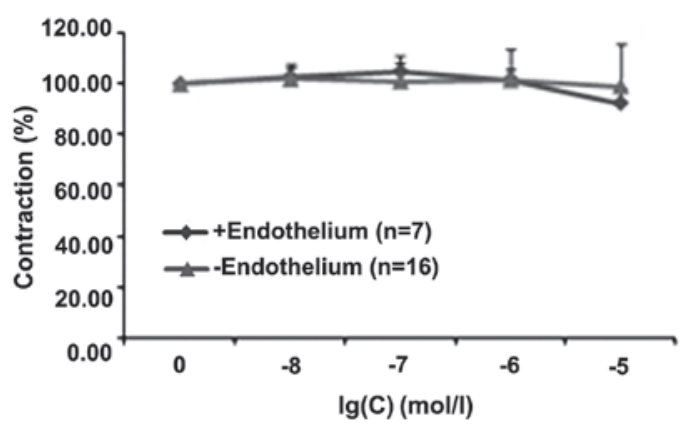

Figure 1. Norepinephrine-induced vasoconstriction of aortic rings with or without endothelium. After being progressively stretched to a basal tension of $2.0 \mathrm{~g}$ and equilibrated for $\geq 90 \mathrm{~min}$, different concentrations of (A) Panax notoginseng saponins, (B) ginsenoside Rg1, (C) ginsenoside Re, (D) ginsenoside Rb1, (E) notoginsenoside R1 and (F) ginsenoside Rd were added cumulatively. ${ }^{* *} \mathrm{P}<0.01$ vs. time 0 .

Table I. Effects of solvent on the vasoconstriction of aortic rings (\%; mean \pm standard deviation).

\begin{tabular}{ccc}
\hline Time (min) & $\mathrm{H}_{2} \mathrm{O}(\mathrm{n}=15)$ & DMSO $(\mathrm{n}=15)$ \\
\hline 8 & $104.13 \pm 3.83$ & $104.04 \pm 2.75$ \\
16 & $105.22 \pm 6.09$ & $107.39 \pm 4.93$ \\
24 & $102.68 \pm 4.95$ & $106.82 \pm 5.97$ \\
32 & $95.31 \pm 5.06$ & $99.98 \pm 7.69$
\end{tabular}

DMSO, dimethylsulfoxide.

effect on the NE-induced vasoconstriction of the rat aortic rings. Mean values of the contraction at four different time points for each solvent are presented in Table I. As detailed in Materials and methods, the test substances $\left(\mathrm{H}_{2} \mathrm{O}\right.$ or DMSO) were delivered every $8 \mathrm{~min}$ and no wash-out was performed during the experiment. Statistical comparison demonstrated that the curves for the two solvents were not significantly different $(\mathrm{P}>0.05)$.
Effects of PNS and its main components on aortic rings with or without endothelium. Whether the endothelium plays a major role in mediating the effect of PNS and its five main components (Rg1, Re, Rb1, R1 and Rd) was then investigated. In Fig. 1, dose-response curves for these compounds are shown; each curve represents the ability of the compound to reduce the tonic contraction induced by $\mathrm{NE}$ in the presence and absence of the endothelium. Results clearly indicate that when the endothelium lining was intact, PNS, Rg1, Re, Rb1 and R1 (Fig. 1A-E, respectively) significantly reduced the tonic contraction (\% of NE) at all doses investigated. The effect was completely lost when the endothelium was absent. Notably, the administration of Rd was not able to induce any response in either the presence or the absence of the endothelium. Detailed statistical comparisons of the data are presented in Table II.

Effects of PNS and its main components on the endothelial NO pathway

Effects of PNS and its main components are partially conserved by $L-N A M E$. In order to evaluate whether endothelial NO plays a significant role in the mediation of the previously observed 
Table II. Effects of PNS and five main components on aortic rings with or without endothelium.

\begin{tabular}{|c|c|c|c|}
\hline \multirow[b]{2}{*}{ Drugs } & \multirow[b]{2}{*}{ Concentration } & \multicolumn{2}{|c|}{ Contraction ( $\%$ of $\mathrm{NE})$} \\
\hline & & Endothelium (n=10-18) & Endothelium-denuded $(\mathrm{n}=10-18)$ \\
\hline \multirow[t]{4}{*}{ PNS (mg/ml) } & 0.2 & $93.02 \pm 9.11^{\mathrm{a}}$ & $100.91 \pm 5.29$ \\
\hline & 0.4 & $80.37 \pm 13.44^{\mathrm{a}}$ & $102.43 \pm 5.37$ \\
\hline & 0.6 & $60.62 \pm 20.71^{\mathrm{a}}$ & $102.73 \pm 4.96$ \\
\hline & 0.8 & $37.19 \pm 25.23^{\mathrm{a}}$ & $96.69 \pm 10.37$ \\
\hline \multirow[t]{4}{*}{$\operatorname{Rg} 1$ (mol/l) } & $1 \times 10^{-8}$ & $83.67 \pm 10.41^{\mathrm{a}}$ & $104.28 \pm 4.50$ \\
\hline & $1 \times 10^{-7}$ & $62.47 \pm 12.07^{\mathrm{a}}$ & $108.68 \pm 8.96$ \\
\hline & $1 \times 10^{-6}$ & $47.61 \pm 17.61^{\mathrm{a}}$ & $108.68 \pm 7.67$ \\
\hline & $1 \times 10^{-5}$ & $34.75 \pm 17.88^{a}$ & $106.68 \pm 8.61$ \\
\hline \multirow[t]{4}{*}{$\operatorname{Re}(\mathrm{mol} / \mathrm{l})$} & $1 \times 10^{-8}$ & $78.50 \pm 12.82^{\mathrm{a}}$ & $101.30 \pm 4.79$ \\
\hline & $1 \times 10^{-7}$ & $60.44 \pm 20.44^{\mathrm{a}}$ & $105.36 \pm 5.20$ \\
\hline & $1 \times 10^{-6}$ & $49.26 \pm 20.63^{\mathrm{a}}$ & $105.97 \pm 7.28$ \\
\hline & $1 \times 10^{-5}$ & $33.63 \pm 20.74^{\mathrm{a}}$ & $100.39 \pm 7.35$ \\
\hline \multirow[t]{4}{*}{ Rbl (mol/l) } & $1 \times 10^{-8}$ & $81.77 \pm 7.78^{\mathrm{a}}$ & $103.24 \pm 3.06$ \\
\hline & $1 \times 10^{-7}$ & $66.69 \pm 16.36^{\mathrm{a}}$ & $104.67 \pm 4.12$ \\
\hline & $1 \times 10^{-6}$ & $52.13 \pm 20.94^{\mathrm{a}}$ & $103.83 \pm 7.21$ \\
\hline & $1 \times 10^{-5}$ & $38.69 \pm 22.79^{a}$ & $95.90 \pm 11.76$ \\
\hline \multirow[t]{4}{*}{$\mathrm{R} 1(\mathrm{~mol} / \mathrm{l})$} & $1 \times 10^{-8}$ & $83.06 \pm 11.58^{a}$ & $103.21 \pm 5.73$ \\
\hline & $1 \times 10^{-7}$ & $62.55 \pm 19.06^{\mathrm{a}}$ & $103.13 \pm 6.19$ \\
\hline & $1 \times 10^{-6}$ & $51.01 \pm 17.96^{\mathrm{a}}$ & $101.90 \pm 6.66$ \\
\hline & $1 \times 10^{-5}$ & $36.04 \pm 19.23^{\mathrm{a}}$ & $99.57 \pm 10.87$ \\
\hline \multirow[t]{4}{*}{$\mathrm{Rd}(\mathrm{mol} / \mathrm{l})$} & $1 \times 10^{-8}$ & $101.87 \pm 5.57$ & $102.78 \pm 3.29$ \\
\hline & $1 \times 10^{-7}$ & $101.06 \pm 10.06$ & $104.93 \pm 3.55$ \\
\hline & $1 \times 10^{-6}$ & $101.52 \pm 12.46$ & $101.73 \pm 3.95$ \\
\hline & $1 \times 10^{-5}$ & $99.06 \pm 16.80$ & $92.43 \pm 5.90$ \\
\hline
\end{tabular}

${ }^{a} \mathrm{P}<0.01$ vs. time 0 . PNS, Panox notoginseng saponins; NE, norepinephrine.

effects of PNS and four of its main components (Rg1, Re, Rb1 and R1), experiments were carried out with L-NAME, which is a compound known to selectively block NO synthase and therefore the pathways downstream of NO production. The results shown in Fig. 2 reveal that pre-incubation of the aortic rings with intact endothelium using L-NAME significantly reduced the effects of the drugs at all concentrations tested $(\mathrm{P}<0.01)$. Detailed statistical comparisons of the data are presented in Table III.

Effects of PNS and its main components are partially conserved by $O D Q$. It was then evaluated whether the endothelial NO-mediated pathway requires the functional integrity of guanylyl cyclase and, therefore, cGMP production. Thus, whether pre-treatment of aortic rings with intact endothelium with ODQ, a selective, irreversible, heme-site inhibitor of soluble guanylyl cyclase and competitive inhibitor of NO, was able to inhibit the effects of PNS, Rg1, Re, Rb1 and R1 was tested. As shown in Fig. 3, pre-incubation of the aortic rings with intact endothelium using ODQ significantly reduced the effects of PNS and four of its main components $(\mathrm{Rg} 1, \mathrm{Re}, \mathrm{Rb1}$ and $\mathrm{R} 1)$ at all concentrations tested $(\mathrm{P}<0.05)$. Detailed statistical comparisons of the data are presented in Table IV.
Effects of PNS and its main components on the COX pathway. In this set of experiments, the involvement of the COX pathway in mediating the effects of PNS, Rg1, Re, Rb1 and R1 was investigated. As shown in Fig. 4, pre-incubation of the rat aortic rings with intact endothelium using INDO, a known COX inhibitor, significantly reduced the effects of PNS, Re and Rb1 $(\mathrm{P}<0.05)$; by contrast, $\operatorname{Rg} 1$ and R1 did not elicit any effects. Detailed statistical comparisons of the data are provided in Table V.

\section{Discussion}

PNS is a traditional Chinese herbal medicine that has protective effects on heart function; particularly, it significantly ameliorates myocardial ischemia-reperfusion injury, reduces myocardial damage, decreases the incidence of irreversible ventricular fibrillation, and protects against myocardial ischemia (33). In addition, PNS has a protective effect on blood vessels; it inhibits the proliferation of vascular smooth muscle, protects the vascular endothelium, lowers blood pressure, and exhibits anti-thrombosis, anti-atherosclerosis and anti-platelet aggregation effects (34). Due to these multiple beneficial effects, PNS is frequently used in Chinese medicine for the treatment of cardiovascular diseases. 
Table III. Effects of PNS and four main components on aortic rings in the presence of L-NAME.

\begin{tabular}{|c|c|c|c|c|}
\hline \multirow[b]{2}{*}{ Drugs } & \multirow[b]{2}{*}{ Concentration } & \multicolumn{3}{|c|}{ Contraction ( $\%$ of NE) } \\
\hline & & $\begin{array}{l}\text { Endothelium } \\
\quad(n=11-15)\end{array}$ & $\begin{array}{l}\text { Endothelium + L-NAME } \\
\qquad(\mathrm{n}=11-15)\end{array}$ & $\begin{array}{l}\text { Endothelium-denuded } \\
\qquad(\mathrm{n}=10-12)\end{array}$ \\
\hline \multirow[t]{4}{*}{ PNS (mg/ml) } & 0.2 & $70.03 \pm 21.71$ & $90.59 \pm 7.80^{\mathrm{a}}$ & $100.91 \pm 5.29$ \\
\hline & 0.4 & $48.39 \pm 25.60$ & $79.81 \pm 14.41^{\mathrm{a}}$ & $102.43 \pm 5.37$ \\
\hline & 0.6 & $47.41 \pm 26.50$ & $75.94 \pm 16.68^{a}$ & $102.73 \pm 4.96$ \\
\hline & 0.8 & $39.30 \pm 27.01$ & $68.23 \pm 21.04^{\mathrm{a}}$ & $96.69 \pm 10.37$ \\
\hline \multirow[t]{4}{*}{$\operatorname{Rg} 1$ (mol/l) } & $1 \times 10^{-8}$ & $86.58 \pm 13.21$ & $95.48 \pm 4.42^{\mathrm{b}}$ & $104.28 \pm 4.50$ \\
\hline & $1 \times 10^{-7}$ & $66.23 \pm 15.37$ & $85.71 \pm 12.67^{\mathrm{a}}$ & $108.68 \pm 8.96$ \\
\hline & $1 \times 10^{-6}$ & $46.96 \pm 18.98$ & $72.85 \pm 19.64^{\mathrm{a}}$ & $108.68 \pm 7.67$ \\
\hline & $1 \times 10^{-5}$ & $35.72 \pm 22.03$ & $60.54 \pm 21.56^{\mathrm{a}}$ & $106.68 \pm 8.61$ \\
\hline \multirow[t]{4}{*}{$\operatorname{Re}(\mathrm{mol} / \mathrm{l})$} & $1 \times 10^{-8}$ & $81.72 \pm 5.53$ & $100.40 \pm 5.53^{\mathrm{a}}$ & $101.30 \pm 4.79$ \\
\hline & $1 \times 10^{-7}$ & $65.98 \pm 7.06$ & $93.49 \pm 7.46^{\mathrm{a}}$ & $105.36 \pm 5.20$ \\
\hline & $1 \times 10^{-6}$ & $54.59 \pm 12.43$ & $74.19 \pm 16.16^{\mathrm{a}}$ & $105.97 \pm 7.28$ \\
\hline & $1 \times 10^{-5}$ & $34.14 \pm 19.26$ & $51.36 \pm 16.36^{b}$ & $100.39 \pm 7.35$ \\
\hline \multirow[t]{4}{*}{ Rbl (mol/l) } & $1 \times 10^{-8}$ & $76.76 \pm 6.63$ & $95.61 \pm 12.15^{\mathrm{a}}$ & $103.24 \pm 3.06$ \\
\hline & $1 \times 10^{-7}$ & $56.99 \pm 16.34$ & $83.97 \pm 19.92^{\mathrm{a}}$ & $104.67 \pm 4.12$ \\
\hline & $1 \times 10^{-6}$ & $45.25 \pm 16.09$ & $66.92 \pm 24.55^{\mathrm{b}}$ & $103.83 \pm 7.21$ \\
\hline & $1 \times 10^{-5}$ & $27.40 \pm 16.61$ & $46.92 \pm 23.21^{\mathrm{b}}$ & $95.90 \pm 11.76$ \\
\hline \multirow[t]{4}{*}{$\mathrm{R} 1$ (mol/l) } & $1 \times 10^{-8}$ & $79.83 \pm 15.76$ & $101.40 \pm 6.26^{\mathrm{a}}$ & $103.21 \pm 5.73$ \\
\hline & $1 \times 10^{-7}$ & $57.67 \pm 21.30$ & $96.26 \pm 10.68^{a}$ & $103.13 \pm 6.19$ \\
\hline & $1 \times 10^{-6}$ & $53.34 \pm 20.68$ & $83.03 \pm 15.84^{\mathrm{a}}$ & $101.90 \pm 6.66$ \\
\hline & $1 \times 10^{-5}$ & $42.40 \pm 23.16$ & $66.02 \pm 23.26^{\mathrm{b}}$ & $99.57 \pm 10.87$ \\
\hline
\end{tabular}

${ }^{\mathrm{a}} \mathrm{P}<0.01,{ }^{\mathrm{b}} \mathrm{P}<0.05$ vs. the group with endothelium. PNS, Panox notoginseng saponins; NE, norepinephrine; L-NAME, $\mathrm{N}^{\mathrm{G}}$-nitro-L-arginine methyl ester.

A

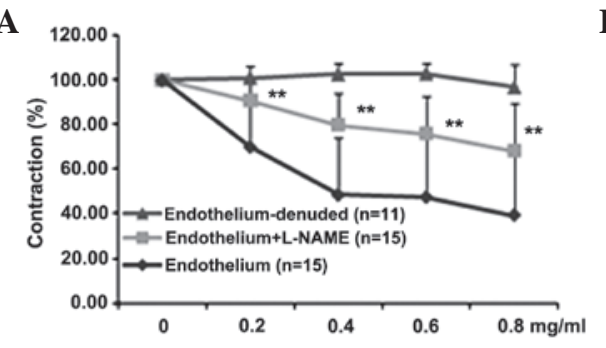

B

D

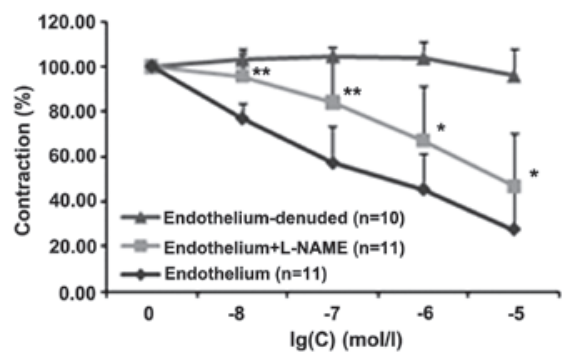

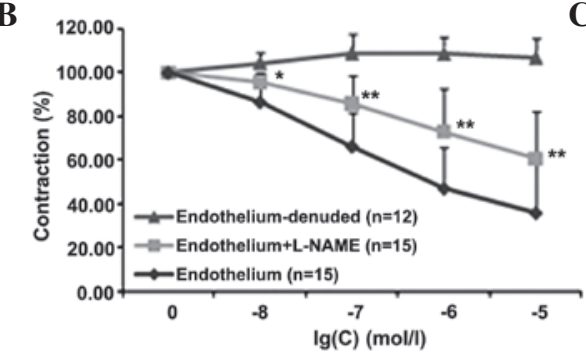

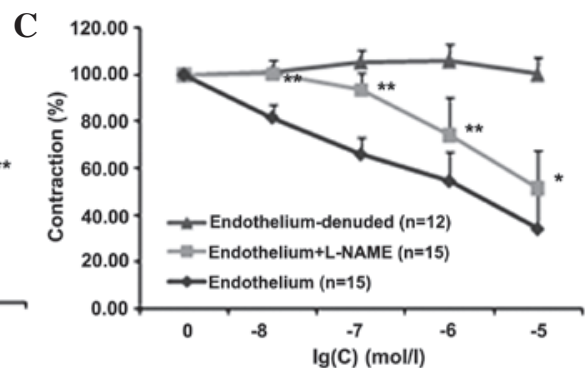

$\mathbf{E}$

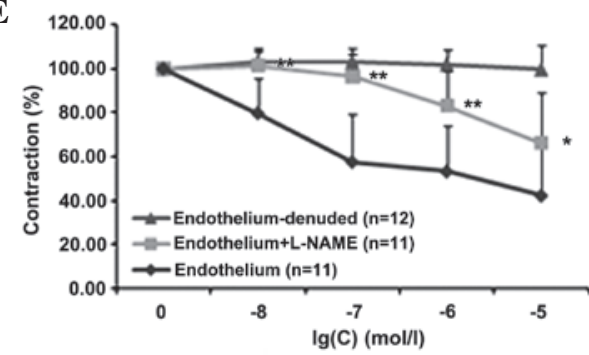

Figure 2. Vasoconstriction of rat aortic rings in the presence and absence of L-NAME. Inhibition of norepinephrine-pre-contracted rat thoracic aorta rings with intact endothelium in response to the cumulative addition of (A) PNS, (B) Rg1, (C) Re, (D) Rb1 and (E) R1 in the presence and absence of L-NAME. PNS, Panax notoginsenoside saponins; L-NAME, $\mathrm{N}^{\mathrm{G}}$-nitro-L-arginine methyl ester. ${ }^{*} \mathrm{P}<0.05,{ }^{* *} \mathrm{P}<0.01$ vs. the group with endothelium.

In the present study, the effects and mechanism of action of PNS and it main five components (Rg1, Re, Rb1, R1 and $\mathrm{Rd}$ ) on rat aorta rings re-contracted with $\mathrm{NE}$ were evaluated.
Ginsenosides $\operatorname{Rg} 1, \mathrm{Re}, \mathrm{Rb} 1$ and Rd and notoginsenoside R1 are all found in the root and rhizome of Panax notoginseng, and they are main components of PNS. Ginsenosides Rg1 
Table IV. Effects of PNS and four main components on aortic rings in the presence of ODQ.

\begin{tabular}{|c|c|c|c|c|}
\hline \multirow[b]{2}{*}{ Drug } & \multirow[b]{2}{*}{ Concentration } & \multicolumn{3}{|c|}{ Contraction (\% of NE) } \\
\hline & & $\begin{array}{l}\text { Endothelium } \\
\qquad(n=9-17)\end{array}$ & $\begin{array}{c}\text { Endothelium + ODQ } \\
\qquad(n=9-17)\end{array}$ & $\begin{array}{l}\text { Endothelium-denuded } \\
\qquad(\mathrm{n}=11-14)\end{array}$ \\
\hline \multirow[t]{4}{*}{ PNS (mg/ml) } & 0.2 & $77.25 \pm 8.74$ & $96.249 \pm 10.18^{\mathrm{a}}$ & $100.91 \pm 5.29$ \\
\hline & 0.4 & $53.15 \pm 24.64$ & $93.82 \pm 12.36^{\mathrm{a}}$ & $102.43 \pm 5.37$ \\
\hline & 0.6 & $43.75 \pm 25.06$ & $83.74 \pm 19.50^{\mathrm{a}}$ & $102.73 \pm 4.96$ \\
\hline & 0.8 & $26.31 \pm 17.15$ & $62.98 \pm 28.98^{a}$ & $96.69 \pm 10.37$ \\
\hline \multirow[t]{4}{*}{$\operatorname{Rg} 1(\mathrm{~mol} / \mathrm{l})$} & $1 \times 10^{-8}$ & $79.48 \pm 10.38$ & $100.59 \pm 4.64^{\mathrm{a}}$ & $104.28 \pm 4.50$ \\
\hline & $1 \times 10^{-7}$ & $49.00 \pm 17.82$ & $98.15 \pm 8.38^{\mathrm{a}}$ & $108.68 \pm 8.96$ \\
\hline & $1 \times 10^{-6}$ & $29.48 \pm 18.62$ & $90.36 \pm 13.49^{a}$ & $108.68 \pm 7.67$ \\
\hline & $1 \times 10^{-5}$ & $13.23 \pm 13.16$ & $68.28 \pm 19.82^{\mathrm{a}}$ & $106.68 \pm 8.61$ \\
\hline \multirow[t]{4}{*}{$\operatorname{Re}(\mathrm{mol} / \mathrm{l})$} & $1 \times 10^{-8}$ & $73.04 \pm 11.74$ & $97.52 \pm 6.79^{a}$ & $101.30 \pm 4.79$ \\
\hline & $1 \times 10^{-7}$ & $51.18 \pm 14.45$ & $94.06 \pm 11.81^{\mathrm{a}}$ & $105.36 \pm 5.20$ \\
\hline & $1 \times 10^{-6}$ & $36.87 \pm 11.64$ & $93.87 \pm 9.34^{\mathrm{a}}$ & $105.97 \pm 7.28$ \\
\hline & $1 \times 10^{-5}$ & $26.38 \pm 14.52$ & $72.73 \pm 14.95^{\mathrm{a}}$ & $100.39 \pm 7.35$ \\
\hline \multirow[t]{4}{*}{$\mathrm{Rb} 1(\mathrm{~mol} / \mathrm{l})$} & $1 \times 10^{-8}$ & $80.01 \pm 8.93$ & $101.39 \pm 10.77^{\mathrm{a}}$ & $103.24 \pm 3.06$ \\
\hline & $1 \times 10^{-7}$ & $66.97 \pm 13.66$ & $95.26 \pm 12.94^{\mathrm{a}}$ & $104.67 \pm 4.12$ \\
\hline & $1 \times 10^{-6}$ & $50.44 \pm 20.56$ & $86.12 \pm 12.67^{\mathrm{a}}$ & $103.83 \pm 7.21$ \\
\hline & $1 \times 10^{-5}$ & $29.81 \pm 24.59$ & $67.31 \pm 17.27^{\mathrm{a}}$ & $95.90 \pm 11.76$ \\
\hline \multirow[t]{4}{*}{$\mathrm{R} 1$ (mol/l) } & $1 \times 10^{-8}$ & $77.64 \pm 9.05$ & $102.81 \pm 6.96^{\mathrm{a}}$ & $103.21 \pm 5.73$ \\
\hline & $1 \times 10^{-7}$ & $53.26 \pm 13.45$ & $95.89 \pm 13.65^{\mathrm{a}}$ & $103.13 \pm 6.19$ \\
\hline & $1 \times 10^{-6}$ & $33.62 \pm 15.63$ & $73.17 \pm 23.19^{a}$ & $101.90 \pm 6.66$ \\
\hline & $1 \times 10^{-5}$ & $12.14 \pm 12.43$ & $46.44 \pm 28.21^{\mathrm{a}}$ & $99.57 \pm 10.87$ \\
\hline
\end{tabular}

${ }^{a} \mathrm{P}<0.01$ vs. the group with endothelium. PNS, Panox notoginseng saponins; NE, norepinephrine; ODQ, ODQ, 1H-[1,2,4]oxadiazolo[4,3-a] quinoxalin-1-one.
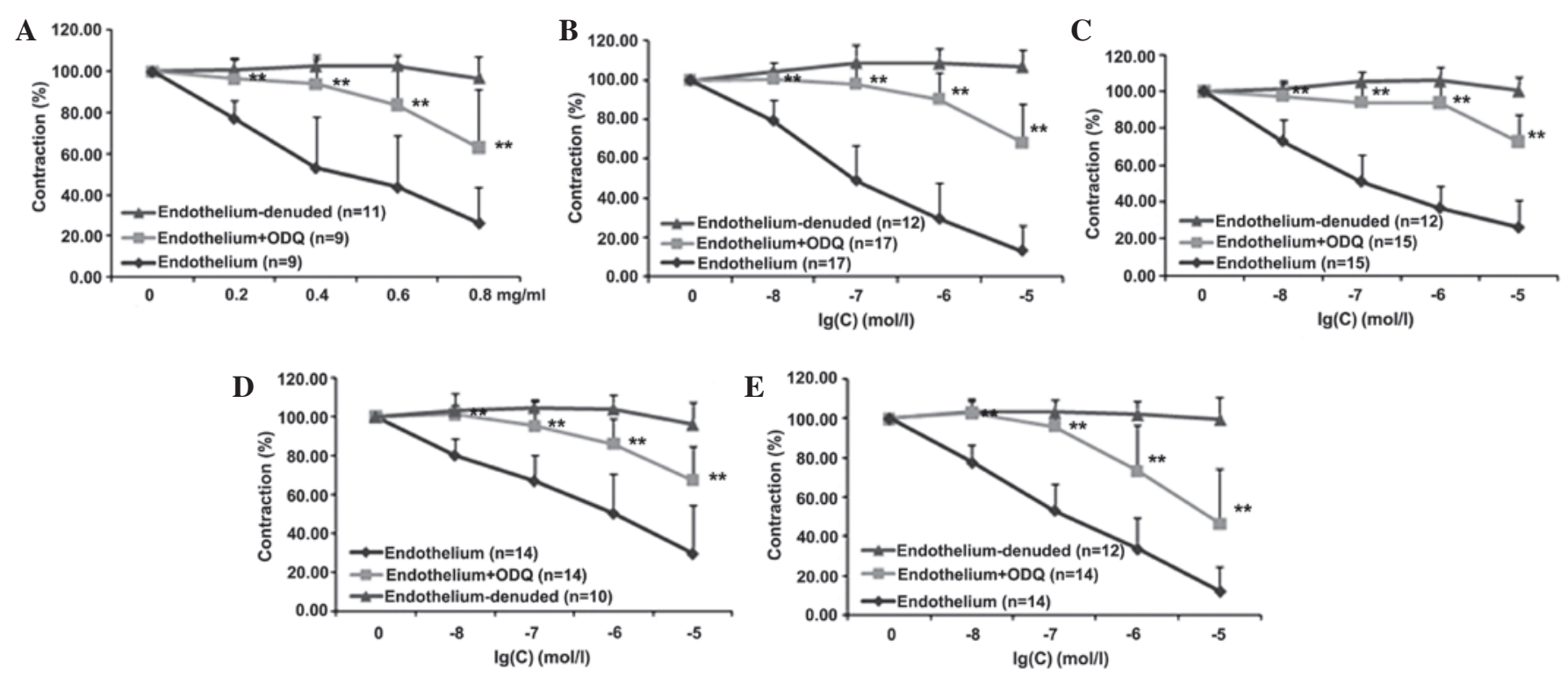

Figure 3. Vasoconstriction of rat aortic rings in the presence and absence of ODQ. Inhibition of norepinephrine-pre-contracted rat thoracic aorta rings with intact endothelium in response to cumulative addition of (A) PNS, (B) Rg1, (C) Re, (D) Rb1 and (E) R1 in the presence and absence of ODQ. PNS, Panax notoginsenoside saponins; ODQ, $1 \mathrm{H}-[1,2,4]$ oxadiazolo[4,3-a]quinoxalin-1-one.** $\mathrm{P}<0.01$ vs, the group with endothelium.

and Rb1 present anti-amnestic and anti-aging effects (35). $\mathrm{Rb} 1$ also plays a role in neurogenesis and the cardiovascular system $(36,37)$. Ginsenoside Re mainly functions in the cardiovascular system, where its effects include changing cardiac electrophysiological properties, which may account for its antiarrhythmic effect (38). Finally, ginsenoside Rd, a 
Table V. Effects of PNS and four main components on the cyclooxygenase pathway in aortic rings.

\begin{tabular}{|c|c|c|c|c|}
\hline \multirow[b]{2}{*}{ Drugs } & \multirow[b]{2}{*}{ Concentration } & \multicolumn{3}{|c|}{ Contraction ( $\%$ of NE) } \\
\hline & & $\begin{array}{l}\text { Endothelium } \\
\qquad(\mathrm{n}=7-10)\end{array}$ & $\begin{array}{l}\text { Endothelium + INDO } \\
\qquad(\mathrm{n}=7-10)\end{array}$ & $\begin{array}{l}\text { Endothelium-denuded } \\
\qquad(\mathrm{n}=10-12)\end{array}$ \\
\hline \multirow[t]{4}{*}{ PNS $(\mathrm{mg} / \mathrm{ml})$} & 0.2 & $77.96 \pm 13.39$ & $86.70 \pm 10.23$ & $100.91 \pm 5.29$ \\
\hline & 0.4 & $54.72 \pm 21.15$ & $77.67 \pm 19.08^{\mathrm{a}}$ & $102.43 \pm 5.37$ \\
\hline & 0.6 & $46.86 \pm 21.48$ & $68.71 \pm 20.56^{\mathrm{a}}$ & $102.73 \pm 4.96$ \\
\hline & 0.8 & $38.79 \pm 18.11$ & $58.69 \pm 18.68^{\mathrm{a}}$ & $96.69 \pm 10.37$ \\
\hline \multirow[t]{4}{*}{ Rg1 (mol/l) } & $1 \times 10^{-8}$ & $87.06 \pm 7.99$ & $84.24 \pm 11.55$ & $104.28 \pm 4.50$ \\
\hline & $1 \times 10^{-7}$ & $67.11 \pm 18.11$ & $65.32 \pm 17.48$ & $108.68 \pm 8.96$ \\
\hline & $1 \times 10^{-6}$ & $54.66 \pm 19.60$ & $61.45 \pm 120.90$ & $108.68 \pm 7.67$ \\
\hline & $1 \times 10^{-5}$ & $46.46 \pm 14.63$ & $54.25 \pm 22.84$ & $106.68 \pm 8.61$ \\
\hline \multirow[t]{4}{*}{$\operatorname{Re}(\mathrm{mol} / \mathrm{l})$} & $1 \times 10^{-8}$ & $85.41 \pm 7.41$ & $100.67 \pm 13.15^{\mathrm{b}}$ & $101.30 \pm 4.79$ \\
\hline & $1 \times 10^{-7}$ & $72.67 \pm 11.16$ & $102.29 \pm 21.72^{b}$ & $105.36 \pm 5.20$ \\
\hline & $1 \times 10^{-6}$ & $57.98 \pm 17.28$ & $99.28 \pm 21.33^{b}$ & $105.97 \pm 7.28$ \\
\hline & $1 \times 10^{-5}$ & $41.47 \pm 21.54$ & $89.04 \pm 17.89^{\mathrm{b}}$ & $100.39 \pm 7.35$ \\
\hline \multirow[t]{4}{*}{ Rb1 (mol/l) } & $1 \times 10^{-8}$ & $91.80 \pm 5.28$ & $95.88 \pm 13.18$ & $103.24 \pm 3.06$ \\
\hline & $1 \times 10^{-7}$ & $80.37 \pm 10.72$ & $105.62 \pm 24.91^{\mathrm{a}}$ & $104.67 \pm 4.12$ \\
\hline & $1 \times 10^{-6}$ & $61.59 \pm 8.39$ & $104.70 \pm 25.69^{b}$ & $103.83 \pm 7.21$ \\
\hline & $1 \times 10^{-5}$ & $56.32 \pm 13.22$ & $91.48 \pm 28.07^{\mathrm{a}}$ & $95.90 \pm 11.76$ \\
\hline \multirow[t]{4}{*}{ R1 (mol/l) } & $1 \times 10^{-8}$ & $84.62 \pm 6.04$ & $82.64 \pm 16.32$ & $103.21 \pm 5.73$ \\
\hline & $1 \times 10^{-7}$ & $62.56 \pm 17.43$ & $62.95 \pm 28.20$ & $103.13 \pm 6.19$ \\
\hline & $1 \times 10^{-6}$ & $49.19 \pm 18.10$ & $53.80 \pm 35.32$ & $101.90 \pm 6.66$ \\
\hline & $1 \times 10^{-5}$ & $40.13 \pm 14.70$ & $44.55 \pm 37.98$ & $99.57 \pm 10.87$ \\
\hline
\end{tabular}

${ }^{\mathrm{a}} \mathrm{P}<0.05,{ }^{\mathrm{b}} \mathrm{P}<0.01$ vs. the group with endothelium. PNS, Panox notoginseng saponins; NE, norepinephrine; INDO, indomethacin.
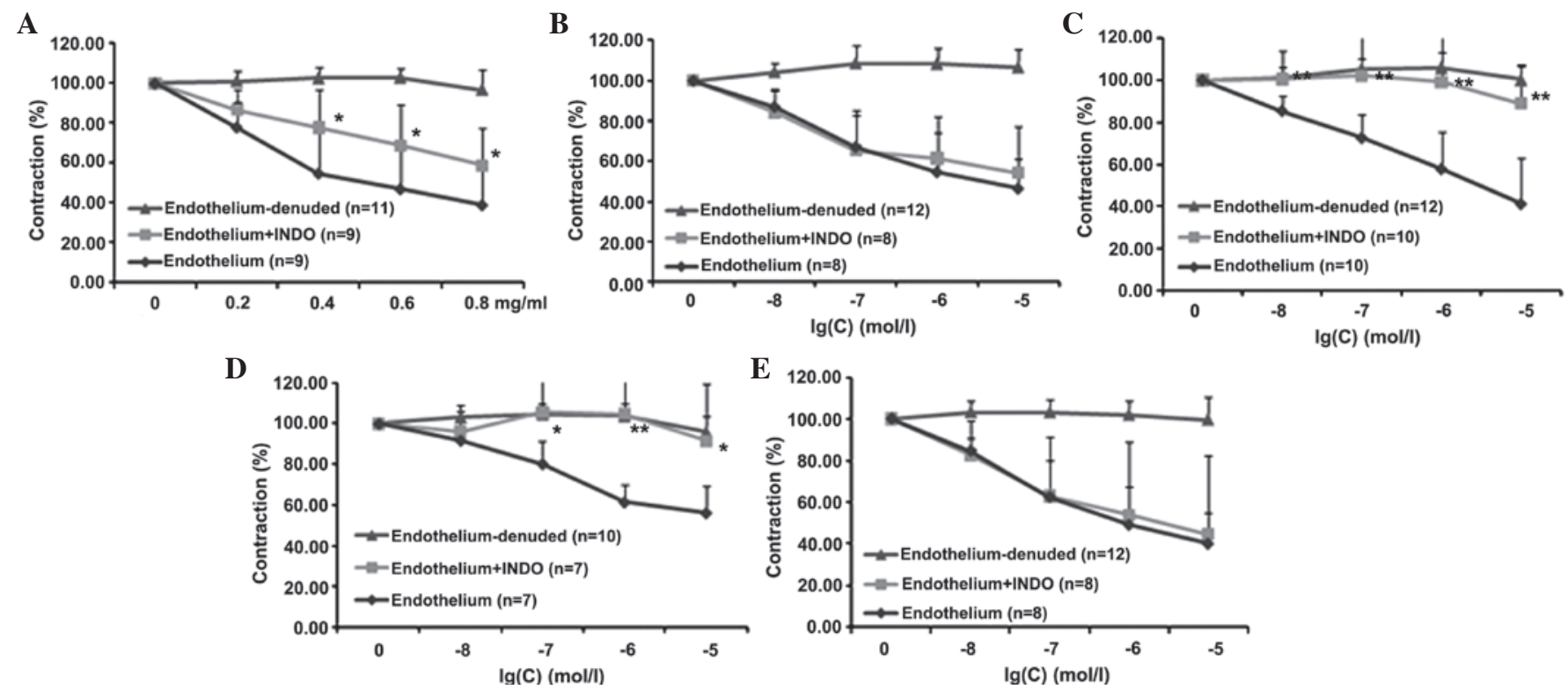

Figure 4. Vasoconstriction of rat aortic rings in the presence and absence of INDO. Inhibition of norepinephrine-pre-contracted rat thoracic aorta rings with intact endothelium in response to cumulative addition of (A) PNS, (B) Rg1, (C) Re, (D) Rb1 and (E) R1 in the presence and absence of INDO. PNS, Panax notoginsenoside saponins; INDO, indomethacin. $\mathrm{P}<0.05,{ }^{* *} \mathrm{P}<0.01$ vs. the group with endothelium.

dammarane-type steroid glycoside, presents a neuroprotective effect on ischemic brain (39). R1 protected the rat heart from I/R-induced structure and function injury, suggesting R1 as a potential adjuvant therapy for patients presenting with acute myocardial infarction (40). Under the experimental conditions used in the present study, PNS, Rg1, Re, Rb1 and R1 induced a 
significant concentration-dependent relaxation, while Rd was not effective at any of the concentrations investigated (Fig. 1).

$\mathrm{NE}$ induces vasoconstriction through increasing intracellular $\mathrm{Ca}^{2+}$ concentration $(41,42)$. It stimulates $\alpha_{1}$ adrenergic receptors located on vascular smooth muscle causing $\mathrm{Ca}^{2+}$ to move into cells through receptor-operated $\mathrm{Ca}^{2+}$ channels as well as $\mathrm{Ca}^{2+}$ release from internal stores $(43,44)$. Increasing intracellular $\mathrm{Ca}^{2+}$ concentration is an important condition for the production of vascular endothelial relaxing factor and the regulation of vascular tone.

The endothelium in blood vessels has been identified to be a critical regulator of vascular tone (45). Endothelial dependence has since been reported for a number of other vasoactive substances $(46,47)$. In particular, it is now known that the vascular endothelium plays a critical role in vascular tone regulation due to its ability to produce both vasoconstrictors (endothelin-1, ATII and thromboxane $\mathrm{A}_{2}$ ) and vasodilation (NO and prostacyclin) factors $(48,49)$. In the present study, it was demonstrated that PNS and four of its main components (Rg1, Re, Rb1 and R1) had vasodilation effects in aortic rings with intact endothelium. By contrast, these vasodilation effects were not present when the endothelium was removed from the aortic rings.

Endothelial cells release various vasodilators to exert their diastolic activity upon being stimulated. Endothelial cells release vasodilators which include the following three main categories: NO, prostaglandin $\mathrm{I}_{2}\left(\mathrm{PGI}_{2}\right)$ and endothelium-derived hyperpolarizing factor (EDHF). NO and $\mathrm{PGI}_{2}$ appear to be important vasodilators as they share a redundancy interaction and they are both activated by multiple compounds and mechanical signals (50). NO is the strongest vasodilator in vascular endothelial cells, and is synthesized by L-arginine via a reaction that is catalytically synthesized by endothelial NO synthase (51). NO is able to activate sGC to produce cGMP which in turn activates protein kinase $\mathrm{G}$ (PKG, also known as cGMP-dependent protein kinase). PKG acts to prevent calcium influx and increase the opening of ATP channels, thus decreasing intracellular $\mathrm{Ca}^{2+}$ levels and ultimately causing vasodilation (52).

L-NAME, an NO synthase inhibitor, reduces the formation of NO and inhibits vasodilation (53). The key enzyme of the NO-cGMP pathway is guanylate cyclase; if guanylate cyclase is inhibited, the NO-cGMP pathway is subsequently blocked and vasodilation is inhibited (54). ODQ, a guanylate cyclase inhibitor, is able to prevent the generation of cGMP and the activation of PKG, thus leading to inhibition of the vasodilation (55). When endothelial cells are stimulated, COX oxidizes arachidonic acid to generate unstable prostaglandin $\mathrm{G}_{2}\left(\mathrm{PGG}_{2}\right)$ and prostaglandin $\mathrm{H}_{2}\left(\mathrm{PGH}_{2}\right)$. Through the action of prostacyclin synthase, $\mathrm{PGG}_{2}$ and $\mathrm{PGH}_{2}$ generate $\mathrm{PGI}_{2}(56)$. $\mathrm{PGI}_{2}$ plays a role in vascular smooth muscle cells by promoting the generation of intracellular cAMP for vasodilation (57). COX is thus a key enzyme for the synthesis of $\mathrm{PGI}_{2}$. INDO is an inhibitor of COX and, through the reduction of this enzyme, reduces the generation of $\mathrm{PGI}_{2}$, thereby interfering with vasodilation.

In the present study, the NO synthase inhibitor L-NAME and the guanylate cyclase inhibitor ODQ were shown to reduce the diastolic effects of PNS and four of its main components ( $\mathrm{Rg} 1, \mathrm{Re}, \mathrm{Rb} 1$ and $\mathrm{R} 1$ ) in aortic rings with intact endothelium (Figs. 2 and 3). It thus may be concluded that these substances cause vasodilation by increasing the production of NO in blood vessels and, furthermore, the endothelium-dependent vasodilation effects of PNS and four of its main components ( Rg1, Re, Rb1 and R1) are exerted upon the guanylate cyclase pathway. INDO, which is a COX inhibitor, is able to block the vasodilatory effects exerted by PNS and ginsenosides Re and Rb1 (Fig. 4). This indicates that PNS, Re and Rb1 may stimulate the release of $\mathrm{PGI}_{2}$ to dilate blood vessels. However, INDO was not found to block the vasodilatory effects of Rg1 and R1, which indicates that the vasodilation effects of $\mathrm{Rg} 1$ and $\mathrm{R} 1$ are not associated with the release of $\mathrm{PGI}_{2}$.

The present study has certain limitations, which are that it was only performed in normal rat aorta in vitro and so it does not best represent hypertensive circumstances or the situation in vivo. Therefore, the conclusions reached in this study require further clarification in future studies.

\section{References}

1. Kim SJ, Lee J, Jee SH, Nam CH, Chun KH, Park IS and Lee SY: Cardiovascular Risk Factors for Incident Hypertension in the Prehypertensive Population. Epidemiol Health 32: e2010003, 2010.

2. Vasan RS, Larson MG, Leip EP, Evans JC, O'Donnell CJ, Kannel WB and Levy D: Impact of high-normal blood pressure on the risk of cardiovascular disease. N Engl J Med 345: 1291-1297, 2001.

3. Chobanian AV, Bakris GL, Black HR, Cushman WC, Green LA, Izzo JL Jr, Jones DW, Materson BJ, Oparil S, Wright JT Jr and Roccella EJ; National Heart, Lung, and Blood Institute Joint National Committee on Prevention, Detection, Evaluation, and Treatment of High Blood Pressure; National High Blood Pressure Education Program Coordinating Committee: The Seventh Report of the Joint National Committee on Prevention, Detection, Evaluation, and Treatment of High Blood Pressure: the JNC 7 report. JAMA 289: 2560-2572, 2010.

4. Erdine S, Ari O, Zanchetti A, Cifkova R, Fagard R, Kjeldsen S, Mancia G, Poulter N, Rahn KH, Rodicio JL, et al: ESH-ESC guideline for the management of hypertension. Herz 31: 331-338, 2006.

5. Toda N, Nakanishi S and Tanabe S: Aldosterone affects blood flow and vascular tone regulated by endothelium-derived NO: Therapeutic implications. Br J Pharmacol 168: 519-533, 2013.

6. Kopincova J, Puzserova A and Bernatova I: Chronic low-dose L-NAME treatment effect on cardiovascular system of borderline hypertensive rats: Feedback regulation? Neuro Endocrinol Lett 29: 784-789, 2008.

7. Tsai AL, Berka V, Sharina I and Martin E: Dynamic ligand exchange in soluble guanylyl cyclase (sGC): Implications for sGC regulation and desensitization. J Biol Chem 286: 43182-43192, 2011.

8. Feelisch M, Kotsonis P, Siebe J, Clement B and Schmidt HH: The soluble guanylyl cyclase inhibitor $1 \mathrm{H}-[1,2,4]$ oxadiazolo[ $[4,3,-\mathrm{a}]$ quinoxalin-1-one is a nonselective heme protein inhibitor of nitric oxide synthase and other cytochrome P-450 enzymes involved in nitric oxide donor bioactivation. Mol Pharmacol 56: 243-253, 1999.

9. Kasznicki J and Wiktorowsha-Owczarek A: Effects of indomethacin on hymodynamic parameters after intravenous administration of propranolol and enalaprilat in rabbits. Pol J Pharmacol 53: 487-493, 2001.

10. Zhang XY, Guo SL and Lv GY: Research progress of the mechanism of antihypertensive Traditional Chinese Medicine. Zhejiang Zhong Yi Yao Da Xue Xue Bao 29: 84-86, 2005 (In Chinese).

11. Wang HQ, Yang HJ and Li ZH: Research progress of antihypertension drug. Jibing Jiance Yu Kongzhi 1: 35-38, 2013 (In Chinese).

12. Bai Y: Evaluation and rational application of antihypertensive drugs. Chifeng Xue Yuan Xue Bao: 88-89, 2007 (In Chinese).

13. Guo HB, Cui XM, An N and Cai GP: Sanchi ginseng (Panax notoginseng (Burkill) F. H. Chen) in China: Distribution, cultivation and variations. Genet Resour Crop Evol 57: 453-460, 2010. 
14. Ng TB: Pharmacological activity of sanchi ginseng (Panax notoginseng). J Pharm Pharmacol 58: 1007-1719, 2006.

15. He L, Chen X, Zhou M, Zhang D, Yang J, Yang M and Zhou D: Radix/rhizoma notoginseng extract (Sanchitongtshu) for ischemic stroke: A randomized controlled study. Phytomedicine 18: 437-442, 2011

16. Zheng X, Deng YH, Feng Y, Liu Y, Yang L, Huang Y, Sun J, Liang W and Guan Y: Pharmacokinetics and safety of ginsenoside Rd following a single or multiple intravenous dose in healthy Chinese volunteers. J Clin Pharmacol 50: 285-292, 2010.

17. Liu J, Wang Y, Qin L, Yu Y and Wang C: Saponins of Panax notoginseng: Chemistry, cellular targets and therapeutic opportunities in cardiovascular diseases. Expert Opin Investig Drugs 23: 523-539, 2014.

18. Uzayisenga R, Ayeka PA and Wang Y: Anti-diabetic potential of Panax notoginseng saponins (PNS): A review. Phytother Res 28 510-516, 2014.

19. Cicero AF, Bandieri E and Arletti R: Orally administered Panax notoginseng influence on rat spontaneous behaviour. J Ethnopharmacol 73: 387-391, 2000.

20. Huang YS, Yang ZC, Yan BG, Hu XC, Li AN and Crowther RS Improvement of early postburn cardiac function by use of Panax notoginseng and immediate total eschar excision in one operation. Burns 25, 35-41, 1999.

21. Wang XJ, Ichikawa $H$ and Konishi $\mathrm{T}$ : Antioxidant potential of qizhu tang, a Chinese herbal medicine, and the effect on cerebral oxidative damage after ischemia reperfusion in rats. Biol Pharm Bull 24: 558-563, 2001.

22. Li XH and Li SH: Effects of total saponins of Sanchi (Panax pseudo-ginseng var. notoginseng) on TNF, NO and its mechanisms. Zhong Cao Yao 307: 514-515, 1999 (In Chinese)

23. Liu S and Chen JX: Study on effects of raw and cooked Panax notoginseng on blood lipids. Acta Pharmacology Sinica 5: 100-103, 1984

24. Chen W, Dang Y and Zhu C: Simultaneous determination of three major bioactive saponins of Panax notoginseng using liquid chromatography-tandem mass spectrometry and a pharmacokinetic study. Chin Med 5: 12, 2010.

25. Wang JR, Yao LF, Gao WN, Liu Y, Yick PW, Liu L and Jiang ZH: Quantitative comparison and metabolite profiling of saponins in different parts of the root of Panax notoginseng. J Agric Food Chem 62: 9024-9034, 2014

26. Wang L, Li Z, Zhao X, Liu W, Liu Y, Yang J, Li X, Fan X and Cheng Y: A network study of Chinese medicine xuesaitong injection to elucidate a complex mode of action with multicompound, multitarget and multipathway. Evid Based Complement Alternat Med 2013: 652373, 2013.

27. Qin F, Yu SL, Zheng Y and Gao YH: Simultaneous determination of ginsenoside $\mathrm{Rg} 1$ and ginsenoside $\mathrm{Re}$ in total saponins of fibrous roots of Panax notoginseng by HPLC-MS/MS Zhongguo Yao Fang 21: 2922-2924, 2010 (In Chinese).

28. Zhang C, Bao J, Li X and Zheng Y: HPLC determination of the amount of ginsenosides in different parts of Panax ginseng C.A.Mey. and P. quiquefolius L. and P. notoginseng (Burk) F.H.Chen. Yao Wu Fen Xi Za Zhi 25: 1190-1194, 2005 (In Chinese).

29. Jiang YQ, Wang Q, Ma SP and Danf XD: Quantitative determination of saponins in the root of Panax pseudoginseng var. notoginseng by HPLC-ELSD and UV spectrophotometry. Zhong Cao Yao 31: 737-739, 2000 (In Chinese).

30. Wan JB, Wang YT and Li SP: Sanqi (Panax notoginseng). In Pharmacological Activity-Based Quality Control of Chinese Herbs. Li SP and Wang YT (eds). Nova Science Publishers,New York, pp179-203, 2008

31. Wan JB, Zhang QW, Ye WC and Wang YT: Quantification and separation of protopanaxatriol and protopanaxadiol type saponins from Panax notoginseng with macroporous resins. Sep Pur Tech 60: 198-205, 2008.

32. Xu SY (ed): Methodology of Pharmacological Experiments 2nd edition. People's Health Publishing House, Beijing, pp886-887, 1994 (In Chinese).

33. Qiao CL, Ding YF and Yang CR: Pharmacologic research progress of notoginseng total saponins. Zhongguo Xian Dai Zhong Yao 11: 25-30, 2012 (In Chinese).

34. Guo WJ, Yang M,Zhu JG, et al: New progress on pharmacological study of Panax notoginsenoside on the cardiovascular effects. Xian Dai Shi Pin Yu Yao Pin Za Zhi 2: 1-4, 2007 (In Chinese).
35. Cheng Y, Shen LH and Zhang JT: Anti-amnestic and anti-aging effects of ginsenoside Rg1 and Rb1 and its mechanism of action. Acta Pharmacol Sin 26: 143-149, 2005.

36. Zhang JT: Nootropic mechanisms of ginsenoside Rg1-influence on neuronal plasticity and neurogenesis. Yao Xue Xue Bao 40: 385-388, 2005 (In Chinese).

37. Zhong ZD, Wang CM, Wang W, Shen L and Chen ZH: Major hypoglycemic ingredients of Panax notoginseng saponins for treating diabetes. Sichuan Da Xue Xue Bao Yi Xue Ban 45 235-239, 2014 (In Chinese).

38. Peng L, Sun S, Xie LH, Wicks SM and Xie JT: Ginsenoside Re: Pharmacological effects on cardiovascular system. Cardiovase Ther 30: e183-1e88, 2012.

39. Ye R, Zhao G and Liu X: Ginsenoside Rd for acute ischemic stroke: Translating from bench to bedside. Expert Rev Neurother 13: 603-613, 2013.

40. He K, Yan L, Pan CS, Liu YY, Cui YC, Hu BH, Chang X, Li Q, Sun K, Mao XW, et al: ROCK-dependent ATP5D modulation contributes to the protection of notoginsenoside NR1 against ischemia-reperfusion-induced myocardial injury. Am J Physiol Heart Circ Physiol 307: H1764-H1776, 2014.

41. Wang H, Qu JT, Zhao X, Guo Y and Mao HP: Vasodilator effect of oroxylin $\mathrm{A}$ on thoracic aorta isolated from rats. Zhong $\mathrm{Xi} \mathrm{Yi}$ Jie He Xue Bao 10: 880-885, 2012 (In Chinese).

42. Martinsen A, Baccelli C, Navarro I, Abad A, Quetin-Leclercq J and Morel N: Vascular activity of a natural diterpene isolated from Croton zambesicus and of a structurally similar synthetic trachylobane. Vascul Pharmacol 52: 63-69, 2010.

43. McFadzean I and Gibson A: The developing relationship between receptor-operated and store-operated calcium channels in smooth muscle. Br J Pharmacol 135: 1-13, 2002.

44. Slish DF, Arvigo R and Balick MJ: Alseis yucatanensis: A natural product from Belize that exhibits multiple mechanisms of vasorelaxation. J Ethnopharmacol 92: 297-302, 2004.

45. Stone DJ and Johns RA: Endothelium-dependent effects of halothane, enflurane and isoflurane on isolated rat aortic vascular rings. Anesthesiology 71: 126-132, 1989.

46. Furchgott RF: The role of endothelium in the responses of vascular smooth muscle to drugs. Annu Rev Pharmacol Toxicol 24: 175-194, 1984.

47. Vanhoutte PM, Rubanyi GM, Miller VM and Houston DS: Modulation of vascular smooth muscle contraction by the endothelium. Annu Rev Physiol 48: 307-320, 1986.

48. Corvol P, Alhenc-Gelas F and Soubrier F: The vascular endothelium, a site of production and metabolism of vasoactive peptides. Med Sci (Paris) 9: 1050-1060, 1993 (In French).

49. Negro R: Endothelial effects of antihypertensive treatment: Focus on irbesartan. Vasc Health Risk Manag 4: 89-101, 2008.

50. Hellsten Y, Nyberg M, Jensen LG and Mortensen SP: Vasodilator interactions in skeletal muscle blood flow regulation. J Physiol 590: 6279-6305, 2012.

51. Wang GZ, Luo XF, Sun B, Hou YL, Li LP, Zheng DD and Qiao GF: Effects and mechanism of the flavonoid glycoside of Polygonum aviculare L. on vascular endothelium relaxation. Haerbin Yi Ke Da Xue Xue Bao 4: 315-318, 2010 (In Chinese).

52. Li YJ, Zhou JW and Bin K: The diastolic mechanism of Gualou Xiebai Banxia Decoction. Zhong Yao Yao Li Yu Lin Chuang 4: 5-7, 2010 (In Chinese)

53. Li XL, Zou XM, Nie G, Song ML and Li G: Roles of neuronal nitric oxide synthase and inducible nitric oxide synthase in intestinal transplantation of rats. Transplant Proc 45: 2497-2501, 2013.

54. Denninger JW and Marletta MA: Guanylate cyclase and the NO/cGMP signaling pathway. Biochim Biophys Acta 1411: 334-350, 1999 .

55. Marinko M, Novakovic A, Nenezic D, Stojanovic I, Milojevic P, Jovic M, Ugresic N, Kanjuh V, Yang Q and He GW: Nicorandil directly and cyclic GMP-dependently opens $\mathrm{K}+$ channels in human bypass grafts. J Pharmacol Sci 128: 59-64, 2015

56. Fang WT, Li HJ, Zhou LS and Su LQ: Prostacyclin signal pathway: Research advances. Guo Ji Yao Xue Yan Jiu Za Zhi 4: 276-278, 2010 (In Chinese).

57. Zhou P, Wang HP and Jiang HD: The Extracts of Cortex Eucammiae induces both directly and endothelium-dependent relaxation in rat thoracic aorta. Zhongguo Xian Dai Ying Yong Yao Xue 3: 182-185, 2007 (In Chinese). 